\title{
Decompressive Surgery for Traumatic Intracranial Hypertension
}

\section{Nobuyuki Akutsu' ${ }^{1 *}$, Hideo Aihara ${ }^{2}$, Masaaki Taniguchi' ${ }^{1}$, Kohkichi Hosoda $^{1}$ and Eiji Kohmura ${ }^{1}$}

${ }^{1}$ Department of Neurosurgery, Kobe University Graduate School of Medicine, Hyogo, Japan ${ }^{2}$ Department of Neurosurgery, Hyogo Prefectural Kakogawa Medical Center, Hyogo, Japan

Keywords: decompressive craniectomy, traumatic brain injury, intracranial hypertension

Intracranial hypertension is the most frequent cause of death or disability following severe traumatic brain injury (TBI). Marked intracranial hypertension due to brain edema reduces the perfusion pressure in capillary blood vessels, leading to hypoxia and further damage to brain tissue through ischemic injury. Thus, intracranial pressure (ICP) monitoring is a recommended standard procedure for the management of severe TBI $[1,2]$. In addition, first-tier therapies, including head elevation, optimized sedation, normalization of arterial carbon dioxide pressure, and the use of mannitol, hypertonic saline, neuromuscular blockade, and external ventricular drainage are used to control ICP [1]. However, many patients with severe TBI have intracranial hypertension that is refractory to these first-tier therapies, and decompressive procedures, including subtemporal decompression, temporal lobectomy, and hemispheric or bilateral decompressive craniectomy are often required to control ICP. Decompressive craniectomy is the strongest therapy for decreasing ICP. Although the efficacy of the above procedures for improving patient outcome remains controversial, several reports have suggested that decreasing ICP is efficacious [3-6].

We previously reported the usefulness of decompressive skinplasty with an artificial dermis in decompressive craniectomy for the management of severe TBI with uncontrollable brain swelling [7]. Although this technique contributed to dramatically decreasing ICP, the Glasgow Outcome Scale score was unchanged at discharge. One possible explanation is that most of our cases had severe diffuse brain injury, and severe functional damage in the brain may have already been present at the time of injury. Another possible explanation is that decompressive craniectomy caused expansion of the swollen brain and axonal stretch [5]. Although decompressive craniectomy has both advantages and disadvantages, we suppose that applying it alone for ICP control in cases of severe traumatic brain swelling has limited utility for improving the prognosis of patients with severe TBI. If overexpansion of the swollen brain enabled by decompressive craniectomy is controlled by other therapies, prognosis may be improved.

Second-tier options, including high-dose barbiturate therapy and mild hypothermia, can be used to control ICP. However, the efficacy of these procedures remains controversial and the side effects are severe $[8,9]$. Okuma et al. reported that intravenous injection of anti-high mobility group box-1 monoclonal antibody (HMGB1 mAb) efficiently reduced acute brain edema following TBI through protection of the blood-brain barrier and inhibition of the inflammatory responses in rats [10]. The 3-h therapeutic window of anti-HMGB1 mAb could be applicable for clinical use. At present, efficient therapies for brain injury and brain, edema targeting specific molecules is lacking. A combination of appropriate surgical and medical therapies that can overcome the current disadvantages may improve prognosis.

ICP monitoring is considered standard care for severe TBI, but Chesnut et al. reported no significant differences in mortality between patients with severe TBI who were treated with a protocol involving ICP monitoring and those treated with a protocol involving imaging and clinical examination [11]. However, these findings must be interpreted with caution. As the authors mention, several patients were without appropriate prehospital care for $1 \mathrm{~h}$ before arriving at the hospital. Thus, the study population may have had less severe brain injury than comparable intensive care unit populations in higher-income countries. In addition, elderly individuals with traumatic brain injury, who are prevalent in high-income countries, were not represented in the study of Chesnut et al. Although the value of knowing ICP precisely is not being challenged, decreasing the ICP did not necessarily contribute to improved prognosis.

Other monitoring techniques such as measurements of cerebral blood flow and brain tissue oxygenation have been reported [12] Decreasing ICP does not reliably improve brain tissue oxygenation. Using brain tissue oxygenation monitoring in addition to ICP monitoring may lead to better outcome after severe TBI.

The efficacy of decompressive surgery for severe TBI in improving prognosis remains unclear. Further examinations are required to investigate the discrepancy between the control of TBI by decompressive surgery and prognosis in patients with severe TBI. A future combination of appropriate surgical and medical therapies that can compensate for disadvantages may improve prognosis of patients with severe TBI.

\section{References}

1. Brain Trauma Foundation, American Association of Neurological Surgeons, Congress of Neurological Surgeons (2007) Guidelines for the management of severe traumatic brain injury. J Neurotrauma 24 Suppl 1: S1-106.

2. Chambers IR, Treadwell L, Mendelow AD (2001) Determination of threshold levels of cerebral perfusion pressure and intracranial pressure in severe head injury by using receiver-operating characteristic curves: an observational study in 291 patients. J Neurosurg 94: 412-416.

3. Aarabi B, Hesdorffer DC, Ahn ES, Aresco C, Scalea TM, et al. (2006) Outcome following decompressive craniectomy for malignant swelling due to severe head injury. J Neurosurg 104: 469-479.

4. Bao YH, Liang YM, Gao GY, Pan YH, Luo QZ, et al. (2010) Bilatera decompressive craniectomy for patients with malignant diffuse brain swelling after severe traumatic brain injury: a 37-case study. J Neurotrauma 27: 341347.

5. Cooper DJ, Rosenfeld JV, Murray L, Arabi YM, Davies AR, et al. (2011) Decompressive craniectomy in diffuse traumatic brain injury. $\mathrm{N}$ Engl $\mathrm{J}$ Med 364: 1493-1502.

*Corresponding author: Nobuyuki Akutsu, Department of Neurosurgery, Kobe University Graduate School of Medicine, 7-5-1 Kusunoki-cho, Chuo-ku, Kobe 650-0017, Japan, Tel: +81-78-382-5966; Fax: +81-78-382-5979; E-mail: nakutsu@med.kobe-u.ac.jp

Received May 17, 2013; Accepted May 23, 2013; Published May 30, 2013

Citation: Akutsu N, Aihara H, Taniguchi M, Hosoda K, Kohmura E (2013) Decompressive Surgery for Traumatic Intracranial Hypertension. J Neurol Neurophysiol S9: 002 doi:10.4172/2155-9562.S9-002

Copyright: $\odot 2013$ Akutsu N, et al. This is an open-access article distributed under the terms of the Creative Commons Attribution License, which permits unrestricted use, distribution, and reproduction in any medium, provided the original author and source are credited. 
Citation: Akutsu N, Aihara H, Taniguchi M, Hosoda K, Kohmura E (2013) Decompressive Surgery for Traumatic Intracranial Hypertension. J Neurol Neurophysiol S9: 002 doi:10.4172/2155-9562.S9-002

6. Münch E, Horn P, Schürer L, Piepgras A, Paul T, et al. (2000) Management of severe traumatic brain injury by decompressive craniectomy. Neurosurgery 47: 315-322

7. Akutsu N, Aihara H, Sakurai A, Kusaka J, Yasuda M, et al. (2013) New technique of decompressive skinplasty with artificial dermis for severe brain swelling: technical note. Neurol Med Chir (Tokyo) 53: 56-60.

8. Chen HI, Malhotra NR, Oddo M, Heuer GG, Levine JM, et al. (2008) Barbiturate infusion for intractable intracranial hypertension and its effect on brain oxygenation. Neurosurgery 63: 880-886.

9. Peterson K, Carson S, Carney N (2008) Hypothermia treatment for traumatic brain injury: a systematic review and meta-analysis. J Neurotrauma 25: 62-71.
10. Okuma Y, Liu K, Wake H, Zhang J, Maruo T, et al. (2012) Anti-high mobility group box-1 antibody therapy for traumatic brain injury. Ann Neurol 72: 373384

11. Chesnut RM, Temkin N, Carney N, Dikmen S, Rondina C, et al. (2012) A trial of intracranial-pressure monitoring in traumatic brain injury. N Engl J Med 367 : 2471-2481.

12. Narotam PK, Morrison JF, Nathoo N (2009) Brain tissue oxygen monitoring in traumatic brain injury and major trauma: outcome analysis of a brain tissue oxygen-directed therapy. J Neurosurg 111: 672-682. 